\title{
Revalidation: a professional imperative
}

GPs could be forgiven for expressing some scepticism about the introduction of revalidation. Substantive proposals for the reform of medical regulation were put forward by the General Medical Council (GMC) in $1997^{1}$ and criteria against which GPs performance could be judged were first published by the RCGP in 2002. ${ }^{2}$ It is 3 years since the Chief Medical Officer described a comprehensive framework to support revalidation ${ }^{3}$ and more than 2 years since the Secretary of State for Health presented detailed recommendations to parliament. ${ }^{4}$ Clinicians have seen proposed launch dates come and go and still there is no certainty about when the process will start.

The recent publication of the RCGP Guide to the Revalidation of General Practitioners ${ }^{5}$ represents an opportunity to re-engage with a process that heralds a significant change in the compact between the medical profession and society. ${ }^{6}$ Being a doctor used to be uncomplicated. You worked hard as a student, joined the medical register when you qualified, and there your name was likely to stay for the rest of your career. The profession determined what it did, within resource constraints controlled by the state, and both the public and government trusted doctors to do their best. ${ }^{7}$

The world has changed. The traditional model of professional self-regulation is deemed to have failed in the past and to be inadequate for the future. ${ }^{3}$ Society wants doctors to be more accountable for what they do and wants greater influence in how they do it. Revalidation is the mechanism by which the profession can respond to these challenges. The medical profession appears to understand the need for change and there is widespread support among doctors for regular assessment of their competence. ${ }^{3}$ Perhaps few are convinced that revalidation is the most efficient way of weeding out the villains of the profession, but most seem willing to see it as a focus for continuing professional development.
The RCGP Guide to the Revalidation of General Practitioners embodies sound educational principles. ${ }^{5}$ It describes how revalidation will be based on explicit standards, focused strongly on the needs of patients and on what happens in dayto-day practice. The emphasis will be on reflection and self-assessment and the peer review component of self-regulation will remain important. It clarifies that revalidation must be a continuous 5-year process and not a periodic 5-yearly process. Many of the elements of revalidation are established components of the current appraisal process and will be familiar to practitioners, including Professional Development Plans (PDPs), clinical audit, significant event audit, patient feedback, and learning from complaints. The trend towards a stronger emphasis on hard data will continue and accelerate.

Other elements are new and may be perceived as more challenging. Feedback from peers and other colleagues using standardised multi-source feedback (MSF) instruments will be a core part of the revalidation portfolio. There will be a stronger emphasis on the extended role of the doctor, particularly relating to leadership and management activities. A system of 'learning credits' is being designed to quantify the learning described in the PDP, based on the expected impact of the learning as well as the time spent at educational events

No longer will critics be able to describe appraisal as an inconsequential 'cosy chat' ${ }^{\prime}$ conducted in private between the appraiser and appraisee. After the transition period, the revalidation portfolio will contain evidence of five 'enhanced' appraisals (that is, more rigorous appraisals deemed fit for revalidation) five PDPs, four reviews of PDPs, two MSFs, two patient surveys, 250 learning credits, and a review of all complaints during the revalidation period. The appraiser will check that the portfolio meets the requirements for revalidation and it will then be reviewed by a local 'responsible officer', probably the medical director of the primary care trust or health board. The responsible officer will make an initial assessment of whether the submission is satisfactory, requires further discussion or raises substantial concerns. The responsible officer will be one member of an assessment trio, working alongside an RCGP assessor and a lay assessor. This group will review a sample of portfolios considered to be satisfactory and all of those that have raised doubts. The role of the GMC Affiliate, proposed in the Chief Medical Officer's original report $^{3}$ and which will probably operate at a regional level, remains unclear. What is clear is that the RCGP will play a central role in the process. Not only will the College provide the assessor for the local panel but it will also be responsible for ensuring that all panel members are properly trained; quality assuring the assessment decisions and establishing a National Adjudication Panel, which will make final decisions about portfolios that the local panel is unable to recommend for GMC approval.

To some GPs this process will be seen as a significant step forward in integrating regulatory and educational approaches to improvement and in maintaining the leading role that the discipline of general practice has played over the last 40 years in the field of education. To others it will appear a bureaucratic nightmare. In a sense it is both. Over the years doctors have proved themselves highly able to deal with bureaucracy, going through the motions, ticking the right boxes and getting on with what they regard as really important. The challenge for those responsible for implementing revalidation is to persuade the medical profession that a willingness to be more explicitly accountable is fundamental to the success of the profession in the future. The time spent by a clinician collecting evidence about what they do and how well they do it, reflecting on this evidence, and devising ways of improving what they 
do, must be seen as a significant part of the work of a professional. If revalidation is perceived to be imposed from above then it will be a dreadful waste of resources. If it is owned by individual doctors then it has great potential.

This potential could be realised in a number of ways. First, GPs must be willing to contribute to the on-going design of revalidation. Current proposals from the College are the result of much work over many years, shaped by pilots and extensive consultation. Nevertheless, a number of questions remain, particularly about the relationship between self- and external assessment and the needs of non-standard GPs. New approaches to quality assurance of appraisal decisions will need to be designed and, as Bowie and colleagues demonstrate on page 484 of this issue, this is wrought with both conceptual and logistic challenges. ${ }^{9}$ At a technical level, the IT systems supporting revalidation will have to become more sophisticated and the rigour of the measurement tools will need to improve. The answers to these challenges will emerge as revalidation is implemented and the process will evolve. Perhaps our collective understanding of the role of trust in modern society will also become clearer. ${ }^{10}$ All doctors have a professional responsibility to contribute to these processes.

Second, those responsible for implementing revalidation need to be clearer about the implications of the assessment decisions. If we accept that it is valid to make an overall assessment of a doctor's abilities, then it is not unreasonable to assume that these abilities will be normally distributed. We do not yet know where to draw the line on what is acceptable performance and who should make this judgement. There are significant legal implications if a decision is made to remove a doctor's licence to practice on the basis of methods of uncertain validity and reliability. Nor do we know what proportion of currently practising doctors should be revalidated without any further action by those undertaking the assessment. We also do not know enough about the interventions that are required to deal with unacceptable performance and whether these interventions are effective. It is not clear whether we will always want to remove the tail of the curve by refusing to license a small proportion of practitioners, or whether we will reach a stage when only formative action is required to maintain an acceptable level of practice. Both public and professional confidence in the process requires a greater clarity about these issues.

Finally, while significant investment has already been made at a national level in the development of revalidation, it also needs to be properly resourced at a local level. Society's desire to downplay the traditional implicit trust that it has placed in the medical profession and replace it with a stronger emphasis on explicit checking $^{10}$ will not come for free. Seeing the time required to produce a portfolio as something to be done outside the normal working day, something to be squeezed around 'proper work', is a sure way of damaging professional ownership. What the costs will be is still unclear but the total costs to the health system are likely to be substantial. They will be incurred at the level of the individual doctor (producing and acting on the portfolio), the practice team (completing the MSF and supporting the individual clinicians), the local health system (investment in infrastructure and training, appraiser time, assessment and remediation processes) and at a national level (the work of the College and the GMC). While revalidation can and must provide long-term benefit to patients, the amount of effort required to deliver revalidation at a practice level may have a negative impact on the short-term interests of the public and the health service.

The best GPs are the ones that are selfaware, willing to be held to account and have a sense of pride in what they do. Revalidation will contribute to all of these characteristics if it is seen by clinicians as a core professional activity and responsibility.

\section{Martin Marshall,}

Director of Clinical Quality,

The Health Foundation, London.

\section{Provenance}

Commissioned; not peer reviewed.

\section{REFERENCES}

1. Catto G. Will we be getting good doctors and safer patients? BMJ 2007; 334: 450.

2. Royal College of General Practitioners and General Practitioners Committee. Good Medical Practice for General Practitioners. London: RCGP, 2002. http://www.rcgp.org.uk/pdf/PDS_Good_Medical_Practice _for_GPs_July_2008.pdf (accessed 15 Jun 2009).

3. Department of Health. Good doctors, safer patients: proposals to strengthen the system to assure and improve the performance of doctors and to protect the safety of patients. A report by the Chief Medical Officer. London: Department of Health, 2006.

4. Secretary of State for Health. Trust, assurance and safety - the regulation of health professionals in the 21 st century. White paper presented to Parliament by the Secretary of State for Health by Command of Her Majesty. London: The Stationery Office, 2007.

5. Royal College of General Practitioners. RCGP Guide to the revalidation of General Practitioners. Version 1.0. London: RCGP, 2009,

6. Ham C, Alberti G. The medical profession, the public, and the government. BMJ 2002; 324: 838-842.

7. Klein R. The new politics of the National Health Service. 3rd edn. London: Longman, 1998.

8. Smith J. The Shipman Inquiry - fifth report: safeguarding patients: lessons from the past proposals for the future. http://www.the-shipmaninquiry.org.uk/fifthreport.asp (accessed 8 Jun 2009).

9. Bowie P, Cameron N, Staples I, et al. Verifying appraisal evidence using feedback from trained peers: views and experiences of Scottish GP appraisers. $\mathrm{Br} \mathrm{J}$ Gen Pract 2009; 59: 484-489.

10. O'Neil O. A question of trust. The BBC Reith Lectures 2002. Cambridge: Cambridge University Press, 2002.

DOI: 10.3399/bjgp09X453486

\section{ADDRESS FOR CORRESPONDENCE}

\section{Martin Marshall}

The Health Foundation, 90 Long Acre London, WC2E 9RA.

E-mail: Martin.Marshall@health.org.uk 